\title{
Adverse effects of moxifloxacin and flunixin meglumine and their combination on pregnant rats
}

\author{
Emad AbdAl-Salam, Rasha A. Abdel-Gelil, Magdy S. Amer
}

Department of Pharmacology, Faculty of Veterinary Medicine, Mansoura University 35516 Mansoura, Egypt

\section{ARTICLE HISTORY \\ Received: 16.08 .2020}

Revised: 06.08 .2021

Accepted: 02.09.2021

Corresponding author: Emad Abd Alsalam; Tel. 009647801444452, E-mail: emadlen@yahoo.com

\begin{abstract}
Objective: To detail an easy approach to identify the changes that moxifloxacin and flunixin meglumine have caused in the dam of female rats.

Design: Randomized controlled experimental study.

Animals: This study was conducted on thirty-five female (170-200 gm) mature white rats (170$200 \mathrm{gm}$ ) and clinically intact, 20 mature male albino rats for the purpose of mating.

Procedures: Once mating has occurred, this is considered the first day of pregnancy. Rats were randomly divided into seven groups 1) a control group 2) The moxifloxacin group 6 days 3 ) the moxifloxacin group 13 days 4 ) the flunixin meglumine group 6 days 5) the flunixin meglumine group 13 days 6 ) the moxifloxacin and flunixin meglumine mg group 6 days 7) the moxifloxacin and flunixin meglumine $\mathrm{mg}$ group on day 13. Rats were killed on the days specified for the sixth day and the thirteenth day. Blood and liver samples were collected for biochemical analysis of blood and tissue for pathological examination.

Results: Moxifloxacin and flunixin meglumine and their combination have been shown to have some negative effects in mothers of rats, so we recommend that caution be exercised when using moxifloxacin and flunixin meglumine during pregnancy. It was found that the tested drugs had caused a significant decrease in superoxide dismutase and glutathione levels compared to the control group. The histopathological examination of mothers, who were given moxifloxacin and flunixin meglumine and their mixtures, showed variable alterations in kidney, liver and placenta.

Conclusion and clinical relevance: From the above it is clear that moxifloxacin and flunixin meglumine and their combination have caused some negative effects for pregnant rats, so we recommend that you use caution when using moxifloxacin and flunixin meglumine during pregnancy.

Keywords: Liver, Antioxidants, Moxifloxacin, Flunixin meglumine
\end{abstract}

\section{INTRODUCTION}

Many drugs may be used during pregnancy for treatment of some diseases [1]. Such drugs may cause some adverse effects on pregnant females and can induce teratogenic effect [2]. Some drugs can cross the placental barrier and enter fetal circulation during pregnancy, so they may produce some sort of fetal abnormalities [3]. Fluoroquinolones are group of antibacterial agents which affect $G+$ Ve and $G-V e$ bacteria. They are used for curing variety diseases (especially of the G.I.T, respiratory and urinary systems). They may be used during pregnancy intentionally or unintentionally [4].

Newer fluoroquinolones are extensively used in veterinary field as they have good efficacy and safety. Moxifloxacin is a new $4^{\text {th }}$ Generation, 8-Methoxy Quinolone with a broad spectrum of activity and bactericidal action by inactivation of bacterial DNA Gyrase. It has in vitro activity against a wide range of Gram-positive and Gram-negative organisms [5]. Many NSAIDs can be joined the antimicrobial agent therapy for treatment of veterinary bacterial diseases for decreasing fever, pain and inflammation. Flunixin meglumine is one of the nonsteroidal anti-inflammatory drugs that are extensively used in veterinary field. It acts by the inhibition of cyclooxygenase, which synthesizes prostaglandin from arachidonic acid [6].

\section{MATERIALS AND METHODS}

\subsection{Animals, housing and feeding}

Thirty-five female albino rats (aging $3-4$ months and weighing 170-200 gm) and twenty male albino rats (4-5month-old and weighing 200-230 gm for mating) were obtained from Laboratory Animals Colony, Helwan, Egypt. The rats were kept under hygienic condition, housed in metal cages and bedded with wood shavings, fed on a balanced ration composed of breed, milk, barely and carrots and watered ad-libitum. They were accommodated to the laboratory conditions for two weeks before being experimented.

\subsection{Drugs}

\section{Moxifloxacin hydrochloride [Avelox $]^{\circ}$}

AVELOX Injection is available in ready-to-use $250 \mathrm{~mL}$ flexi bags as a sterile, preservative free, $0.8 \%$ sodium chloride aqueous solution of moxifloxacin hydrochloride (containing $400 \mathrm{mg}$ moxifloxacin) with $\mathrm{pH}$ ranging from 4.1 to 4.6 .

Dose: The recommended dose of moxifloxacin for rats is 5 $\mathrm{mg} / \mathrm{kg}$ intramuscularly [7].

Flunixin meglumine [Flunixin] 
A vial contains $50 \mathrm{ml}$ of Flunixin meglumine (Norbrook Company, UK). Each milliliter of Flunixin Injection contains flunixin meglumine equivalent to $50 \mathrm{mg}$ flunixin, $0.1 \mathrm{mg}$ edetate disodium, $2.5 \mathrm{mg}$ sodium formaldehyde sulphoxylate, $4.0 \mathrm{mg}$ diethanolamine, 207.2 $\mathrm{mg}$ propylene glycol, $5.0 \mathrm{mg}$ phenol as preservative, hydrochloric acid, water for injection q.s.

Dose: The recommended dose of flunixin meglumine for rats is $2.5 \mathrm{mg} / \mathrm{kg}$ by S.C [8].

\subsection{Experimental design}

The pregnant rats were allocated randomly into 7 groups (10 dams each) as the following: The control group (G1) was administered saline subcutaneously $5 \mathrm{mg} / \mathrm{kg}$ b.wt. The second group (G2): given moxifloxacin $5 \mathrm{mg} / \mathrm{kg}$ b.wt intramuscular, once daily, at 6th day of gestation for 7 consecutive days. The third group (G3): given flunixin meglumine $2.5 \mathrm{mg} / \mathrm{kg}$ b.wt. Subcutaneously, once day by day, at 6th day of gestation for 7 days. The fourth group (G4): given flunixin meglumine $2.5 \mathrm{mg} / \mathrm{kg}$ b.wt. Subcutaneous, and moxifloxacin $5 \mathrm{mg} / \mathrm{kg}$ b.wt intramuscular once day by day, at 6 th day of gestation for 7 days. The fifth group (G5) given flunixin meglumine $2.5 \mathrm{mg} / \mathrm{kg}$ b.wt. Subcutaneous, when every day, the thirteenth day of development for seven days. The sixth group (G6): given flunixin meglumine $2.5 \mathrm{mg} / \mathrm{kg}$ b.wt. Subcutaneous, and moxifloxacin $5 \mathrm{mg} / \mathrm{kg}$ b.wt intramuscular once day by day, The sixth day of incubation for seven days. The seventh group (G7): given flunixin meglumine $2.5 \mathrm{mg} / \mathrm{kg}$ b.wt. Subcutaneous, and moxifloxacin $5 \mathrm{mg} / \mathrm{kg}$ b.wt intramuscular once every day, the thirteenth day of incubation for seven days. The female rats were kept under daily observation until the 20th day of gestation.

\subsection{Evaluation}

\subsubsection{Blood samples}

On $20^{\text {th }}$ day of pregnancy, 5 rats from each group were subjected to anesthesia by using ketamine hydrochloride and fresh blood samples were immediately collected from eye plexus by syringes collected in centrifuge tubes, then put in refrigerator overnight and then centrifuged at 3000 r.p.m for 10 minutes and clear sera were separated

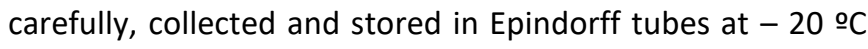
until biochemical analysis [9].

\subsubsection{Biochemical analysis}

Effects of the tested drugs on oxidant and antioxidant activities:

\subsubsection{Determination of catalase activity}

Plasma and amniotic liquid catalase action were resolved by the strategy depicted by [10].

2.4.2.2. Determination of superoxide dismutase (SOD) activity
Superoxide dismutase (SOD) movement in both serum and amniotic liquid were distinguished by the strategy depicted by [11].

\subsubsection{Determination of glutathione reduced (GSH)}

Glutathione reduced (GSH) was measured spectrophotometrically by enzymatic colorimetric method by using ready-made Bio-diagnostic kits according to [12].

\subsubsection{Histopathological studies}

Specimens from liver, kidney and placenta from dams were collected on $20^{\text {th }}$ day of pregnancy and preserved in $20 \%$ neutral buffered formalin for histopathological examination according to [13]. The slides were examined under a photomicroscope fitted with an Olympus DP25 digital camera.

\subsection{Statistical analysis}

The data was analyzed by using computerized SPSS program version 16 . Results are presented as mean $\pm \mathrm{SE}$. The data were analyzed by one way ANOVA following by Duncan's test $p \leq .05$ were considered significant [14].

\section{RESULTS}

3.1. Effect of the tested drugs on the levels of catalase, glutathion and superoxide dismutase in serum tretated dams:

The effects of moxifloxacin ( $5 \mathrm{mg} / \mathrm{kg}$ B. Wt.), flunixin meglumine $(2.5 \mathrm{mg} / \mathrm{kg} \mathrm{B}$. Wt. $)$ and their combination on serum levels of catalse, glutathion and superoxide dismutase of treated groups compared with the control group were presented in Table (1) and illusterated in Figure (1).

\subsection{Serum catalase levels}

The recorded data reflected a non significant decrease $(P<0.05)$ in serum catalase levels in moxifloxacin medicated group $(1.31 \pm 0.08)$ compared with the result of control group $(1.67 \pm 0.08)$. While a significant decrease in serum catalase levels were recoreded in seum of flunixin meglumine $(1.28 \pm 0.08)$ and moxifloxacin with flunixin meglumine (1.06 \pm 0.04$)$ treated groups in comparison with the control group $(1.67 \pm 0.08)$.

\section{3.serum glutathione levels}

The results revealed a significant decrease $(P<0.05)$ in serum glutathione levels in groups treated with moxifluxacin (78.20 \pm 1.87), flunixin meglumine (72.31 \pm 2.50) and moxifloxacin with flunixin meglumine (56.66 \pm 2.52) compared with the serum glutathion level of control group $(91.20 \pm 2.14)$.

\subsection{Serum superoxide dismutase level}

The serum levels of superoxide dismutase were significantly decreased $(\mathrm{P}<0.05)$ in all treated groups, where the levels were $45.61 \pm 1.86$ (with moxifloxacin), $43.31 \pm$ 1.50 (with flunixin meglumine) and were $36.56 \pm 1.13$ (with 
the combination of moxifluxacin flunixin meglumine) compared with that recorded in the control group (60.84 \pm 2.19).

Table 1. Effect of moxifloxacin ( $5 \mathrm{mg} / \mathrm{kg}, \mathrm{I.M}$ ), flunixin meglumine $(2.5 \mathrm{mg} / \mathrm{kg}, \mathrm{S} . \mathrm{C})$ and their combination on $13^{\text {th }}$ day of gestation on serum catalase (CAT), glutathione (GSH) and superoxide dismutase (SOD) levels of treated dams.

\begin{tabular}{|c|c|c|c|}
\hline Group & $\begin{array}{l}\text { Catalase } \\
(\mathrm{U} / \mathrm{ml})\end{array}$ & $\begin{array}{l}\text { GSH } \\
(\mu \mathrm{mol} / \mathrm{ml})\end{array}$ & $\begin{array}{l}\text { SOD } \\
(\mathrm{U} / \mathrm{ml})\end{array}$ \\
\hline Control & $1.67 \pm 0.08 \mathrm{a}$ & $91.20 \pm 2.14 a$ & $\begin{array}{l}60.84 \pm 2.19 \\
a\end{array}$ \\
\hline Moxifloxacin & $1.14 \pm 0.13 a$ & $68.10 \pm 1.28 b$ & $\begin{array}{l}40.63 \pm 2.07 \\
b\end{array}$ \\
\hline $\begin{array}{l}\text { Flunixin } \\
\text { meglumine }\end{array}$ & $1.12 \pm 0.11 \mathrm{a}$ & $66.41 \pm 3.31 b c$ & $\begin{array}{l}39.62 \pm 0.89 \\
b\end{array}$ \\
\hline $\begin{array}{l}\text { Moxifloxacin } \\
+ \text { Flunixin }\end{array}$ & $0.98 \pm 0.11 \mathrm{a}$ & $50.03 \pm 2.17 c$ & $\begin{array}{l}31.30 \pm 1.31 \\
b\end{array}$ \\
\hline Significance & 0.2 N. S & 0.0005 & 0.0012 \\
\hline
\end{tabular}

\subsection{Histopathological findings}

Specimens from liver, kidney, placenta from dams and liver,were collecting on 20th day of pregnancy were preserved in $20 \%$ neutral buffered formalin for 48 hours then washed over night by running water. Tissue samples were dehydrated by using ascending grades of ethyl alcohol starting with $50 \%$ ending with 3changes of absolute alcohol. The tissue samples were left for 12 hours in each grade. The samples were put in xylol for 3 hours for clearing. Specimens were transferred in methyl paraffin wax for $2 \mathrm{hr}$. Finally, the samples were blocked in hard paraffin and cut into sections of 5 microns thickness, stained by Hematoxyline and Eosin stain (H\&E), then mounted by Canada balsam and covered by cover slides [15]. The slides were examined under a photomicroscope fitted with an Olympus DP25 digital camera.

Administration of moxifloxacin, flunixin meglumine and their combination on kidney, liver and placenta of pregnant rats showed the following results.

\section{DISCUSSION}

The exposure of animals to a considerable number of potential toxicants as drugs and chemicals is considered unsuitable to the process adverse effects [16].

A new fluoroquinolone antibacterial for the treatment of respiratory tract infections is known as moxifloxacin. Moxifloxacin as a $4^{\text {th }}$ generation antibacterial agent has a bactericidal effect with broad spectrum activity against $\mathrm{G}$ $\mathrm{Ve}$ and $\mathrm{G}+\mathrm{Ve}$ activity [17]. Flunixin meglumine is a potent non-steroidal anti-inflammatory, that relief pain in painful procedures by inhibiting the production of PGE2 from arachidonic acid [18].
Superoxide Dismutase (SOD), Hydrogen Peroxide $\left(\mathrm{H}_{2} \mathrm{O}_{2}\right)$, and Hydroxyl Radical $(\mathrm{OH})$ as reactive oxygen species (ROS) are reactive oxidant species. They are by-products of intracellular metabolic processes that producing macromolecular damage. They are harmful to health and cause damage to DNA, RNA, proteins, and lipids. Superoxide dismutase (SOD), catalase (CAT), and glutathione peroxidase (GPX) are 3 main antioxidant enzymes in animals. Glutathione is an important endogenous antioxidant with numerous cellular functions that protect against harmful effects of ROS and free radicals. SOD is the first enzyme in the antioxidative system and increases in inflammation and pain. GSH plays a role in the antioxidant defense system by eliminating the reactive oxygen species formed in the living organism, acts as non-enzymatic and SOD enzymatic antioxidant [19].

The results recorded a non significan decrease in the activity of catalase and a marked reduction in glutathione (GSH) and superoxide dismutase (SOD) activities in moxifloxacin treated tats after its s.c administration at 5 $\mathrm{mg} / \mathrm{kg}$ at $6^{\text {th }}$ day of pregnancy which may lead to increased oxidative stress and lipid peroxidation, as well as decreased activity of the detoxification enzyme.

The decreased activity of GSH and SOD in rats treated with the moxifloxacin is attributed to the response of organs to the elevated ROD production, as a result of exposure to the drug and its metabolites. Glutathione (GST) is a multifunctional enzyme and one of the key enzymes in drug metabolism, which is also known to play a vital role in redox balance in the cell [20]. The effect of quinolones as bactericidal initiates the production of the free radicals in both $G-V e$ and $G+V e$ bacteria as end product of drug biotransformation [21]. The GSH level in the liver is a measure of non-enzymatic anti-oxidant and cellular Redox Status of the cells [22]

The observed reduction in GSH levels are in accordance with the previously recorded data by many fluoroquinolones [23] . Also, quinolones have the capacity to produce free radicals and change the activity of antioxidant enzymes [24].Moreover, [25] said that, gatifloxacin significantly decreased the activity of superoxide dismutase and blood glutathione levels of treated rabbits. In addition [26]. mentioned that, moxifloxacin evoked a marked reduction in the activities of Superoxide Dismutase, and Glutathione in treated tats.

In the same direction, flunixin meglumine and its combination with moxifloxacin evoked a non-significant decrease in catalase level and a marked reduction in Superoxide Dismutase and glutathione of treated dams. These findings are in accordance with those recorded by [27].who mentioned that, Flunixin meglumine induced significant decrease in GSH and SOD levels. Moreover, [28]. stated that, ibuprofen and diclofenac showed a significant decrease in GSH level of treated fish. In addition, [28]. reported that, celecoxib as non-steroidal anti-inflammatory 
induced a significant reduction in levels of SOD and GSH of tested rats.
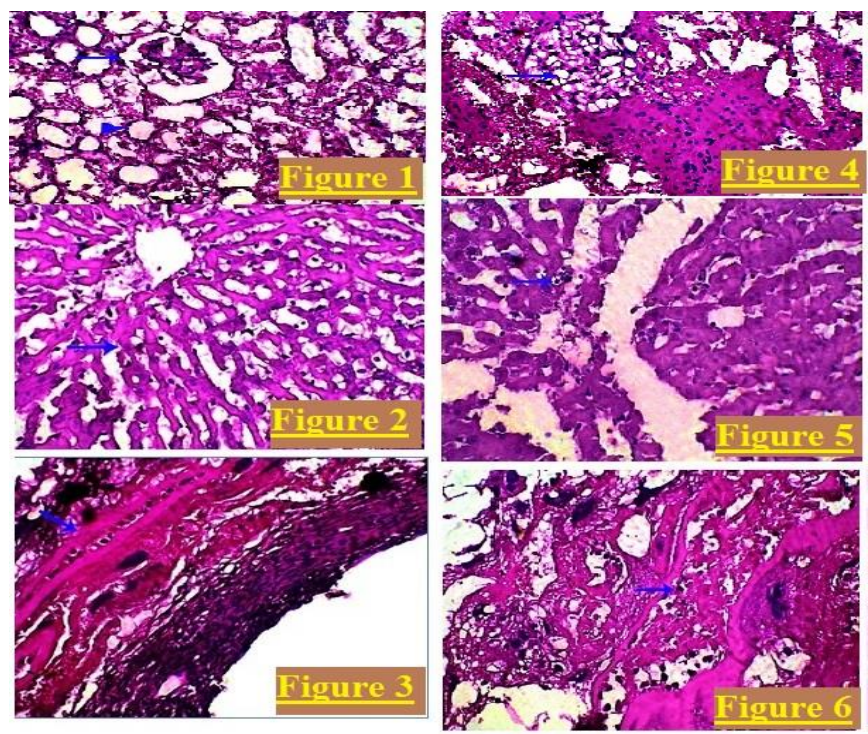

Figure 1. Kidney of dam displays normal renal glomeruli (arrow) and normal renal tubules (arrowhead). (H\&E, 400X). Figurer 2. Liver of dam displays normal hepatocytes in normal radial arrangement around central vein (arrow). (H\&E, 400X). Figure 3. Placenta of dam showing normal histological structure with normal blood vessels (arrow). (H\&E, 400X). Figure 4. The kidney of dam given moxifloxacin displayed congestion of the renal glomeruli (arrow) and degenerative changes of the renal tubular epithelium. (H\&E, 400X). Figure 5. The liver of dam given moxifloxacin displays lytic necrosis of hepatocytes and lymphocytic infiltrates (arrow). (H\&E, 400X). Figure 6. The placenta of dam given moxifloxacin displays neutrophils infiltration (arrow). (H\&E, 400X).

The recorded results regarding the histopathological study in this work revealed that, the given moxifloxacin to pregnant rats at $6^{\text {th }}$ day of gestation period showed different alterations in liver (lytic necrosis of hepatocytes, lymphocytic infiltrates, dilatation of hepatic sinusoids and edema in sub-endothelial around central vein) and kidney (congestion of the renal glomeruli, degenerative changes of the renal tubular epithelium and hemorrhage in interstitial tissues) of treated dams. Moxifloxacin induced some changes in placenta of the treated Dams (neutrophilic infiltration and the blood vessels plugged with neutrophils).

The result regarding the effect of moxifloxacin on liver is similar to that obtained by many investigators [29]. found that, fluoroquinolones showed severe liver damage (extensive hepatocellular necrosis and a mixed inflammatory infiltrate with abundant eosinophil) [30]. reported that ciprofloxacin administration during gestation evoked severe liver damage in Westar albino rats. In addition [31]. said that oral administration of norfloxacin during pregnancy revealed congestion in central and portal vein associated with edema and inflammatory cells infiltration in liver. Moreover, [32]. revealed that ciprofloxacin caused histological changes in liver of pregnant rats (dilatation of central and portal vein, and appearance of macrophages and Kupffer cells in sinusoidal spaces with congested blood vessels. Further, [33]. mentioned that norfloxacin showed some histopathological alterations in liver, kidney, heart, spleen and intestine of treated dams. The accumulation of antimicrobials in the kidneys can induce sever damage (as tubular injury, interstitial inflammation, alterations in renal electrolyte levels and glomerular apparatus damage [34]. The results of moxifloxacin on kidney are in accordance with the findings of [35]. who reported mild interstitial nephritis associated with fluoroquinolones, norfloxacin, ciprofloxacin and nofloxacin. Also, [36-38]. reported that, norfloxacin showed glomerular olization in the lining epithelium of the renal tufts while the intertubular tissue showed focal hemorrhages in kidney after its oral administration.

The induced pathological changes in placenta might be attributed to toxic of the drug as it pass easily through placenta due to its low molecular weight [33]. The result is supported by [39]. who stated that the given norfloxacin to pregnant rats showed necrosis in the placenta (giant cells figure with focal hemorrhages in labyrinth layer) and the uterus showed desquamation of endometrial epithelium.

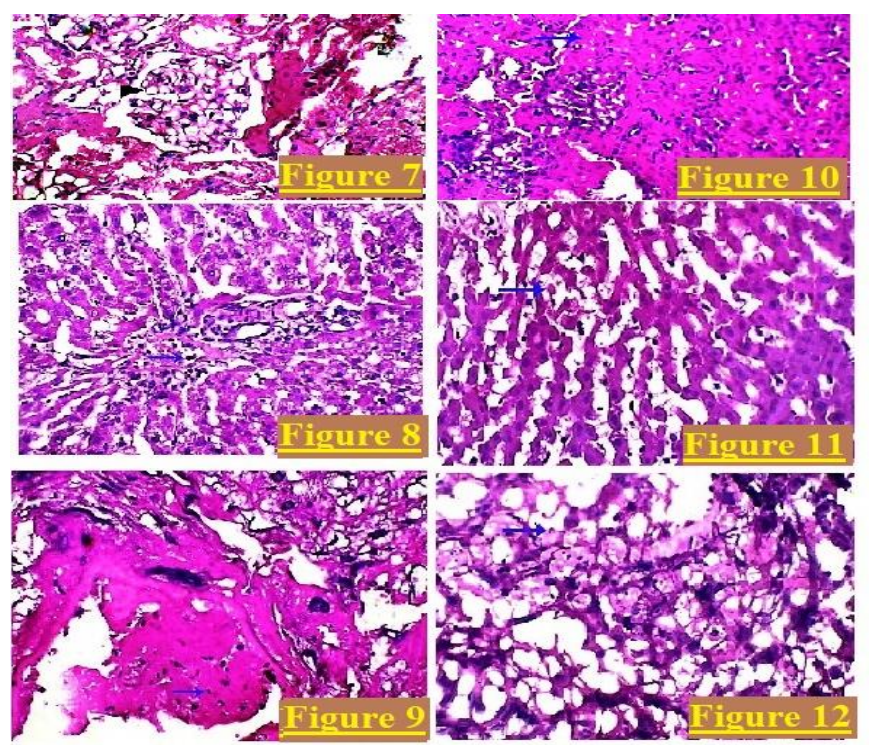

Figure 7. The kidney of dam given flunixin meglumine showing necrosis of renal tubular epithelium lining renal tubules (arrow) and slight congestion of the renal glomeruli (arrowhead). (H\&E, 400X). Figure 8. The liver of dam given flunixin meglumine showing swollen endothelial cells and lymphocytic adherence to it (arrow). (H\&E, 400X). Figure 9. The placenta of dam given flunixin meglumine showing polymorph nuclear cell infiltration (arrow). (H\&E, 400X). Figure 10. The kidney of dam given moxifloxacin with flunixin meglumine showed degenerative change in the renal tubular epithelium (H\&E, 400X). Figure 11. The liver of dam given moxifloxacin with flunixin meglumine showed dilation of hepatic sinusoids with dissociation and necrosis of hepatocyte. Figure 12. The placenta of dam given moxifloxacin with flunixin meglumine showing congestion and degenerated neutrophils (arrow). (H\&E, 400X).

The effects of flunixin meglumine on liver, kidney and placenta of pregnant dams were recorded. The liver of dam given flunixin meglumine showed swollen endothelial cells and lymphocytic adherence to it and showed vacillation of hepatocytes. The kidney of dam given flunixin meglumine showed necrosis of renal tubular epithelium lining renal tubules and slight congestion of the renal glomeruli and showed proliferation of the renal glomeruli. The placenta of dam given flunixin meglumine showed polymorph nuclear cell infiltration and showed severe neutrophil infiltration. The mechanism by which NSAIDs as diclofenac and 
ibuprofen induced hepatotoxicity [39]. who said that nonsteroidal anti-inflammatory inducing liver injury. The obtained data are supported [40] who reported that, the use of mefenamic acid revealed variable histopathological alterations as mild hepato-cellular necrosis with increased liver weight. Moreover, [38]. noticed that liver sections of piroxicam treated mice showed inflammatory cellular infiltration, vacuolated hepatocytes, dilated sinusoids, and increased number of Kupffer cells. In addition, [41]. The effect of flunixin meglumine on kidney tissues is supported by [42] who recorded renal papillary necrosis in kidney of horse on by phenylbutazone. In addition. [3] mentioned that, piroxicam evoked some cellular inflammations, shrunken glomeruli, edema and vacuolation in the tubular cells of the kidney [3].stated that, meloxicam revealed swelling in the endothelial cells lining the tufts associated with degeneration and necrosis in the tubular lining epithelium of the glomeruli of kidney.

\section{Conclusion}

It could be concluded that, administration of moxifloxacin and flunixin meglumine to pregnant rats induced some adverse effects on dams. So, we recommend that neither moxifloxacin nor flunixin meglumine should be used together during pregnancy because of their negative effects.

\section{Acknowledgement}

Authors would like to express deepest gratitude to Delta Water Magnetic Water Treatment Corporation for supporting this work by providing us with the device to conduct the current study.

\section{Conflict of interest statement}

The authors declare that they have no conflict of interest.

\section{Ethical approval}

The current study complies with national and international guidelines. The current study was approved by the research ethics committee at Mansoura university Code No: R/78.

\section{Authors' contribution}

All authors are equally contributed.

\section{REFERENCES}

[1] Al-Myahi A, AL-Musawy A, Al-Snafi AE. Embryotoxicity of fluoroquinolones in rats. Thi-Qar Medical Journal. 2011;5:77-86

[2] Jamkhande PG, Chintawar KD, Chandak PG. Teratogenicity: a mechanism based short review on common teratogenic agents. Asian Pacific Journal of Tropical Disease. 2014;4:421-32. https://doi.org/10.1016/S2222-1808(14)60600-9

[3] Elkomy A, Abo Salem M, Kandeil AM, Hassan A, Elhemiely A. Teratogenic Effect of Meloxicam on Pregnant Rats: Implication of Organogenesis Period. Benha Veterinary Medical Journal. 2018;35:317-27. https://doi.org/10.21608/bvmj.2018.96315

[4] Mehlhorn AJ, Brown DA. Infectious Diseases: Safety Concerns with Fluoroquinolones. Annals of Pharmacotherapy. 2007;41:1859-66. https://doi.org/10.1345/aph.1K347
[5] Miravitlles M. Moxifloxacin in the management of exacerbations of chronic bronchitis and COPD. International journal of chronic obstructive pulmonary disease. 2007;2:191.

[6] Meek IL, Van de Laar MA, E Vonkeman H. Non-steroidal antiinflammatory drugs: an overview of cardiovascular risks. Pharmaceuticals. 2010;3:2146-62. https://doi.org/10.3390/ph3072146

[7] Patel SD, Sadariya KA, Gothi AK, Patel UD, Gohil PA, Jain MR, et al. Effect of moxifloxacin administration on pharmacokinetics of tolfenamic acid in rats. Brazilian Archives of Biology and Technology. 2011;54:739-44. https://doi.org/10.1590/S1516-89132011000400013

[8] Tubbs JT, Kissling GE, Travlos GS, Goulding DR, Clark JA, King-Herbert AP, et al. Effects of buprenorphine, meloxicam, and flunixin meglumine as postoperative analgesia in mice. Journal of the American Association for Laboratory Animal Science. 2011;50:185-91.

[9] Stoffregen D, Wooster G, Bustos P, Bowser P, Babish J. Multiple route and dose pharmacokinetics of enrofloxacin in juvenile Atlantic salmon. Journal of Veterinary Pharmacology and Therapeutics. 1997;20:111-23. https://doi.org/10.1046/j.1365-2885.1997.81531.x

[10] Sinha AK. Colorimetric assay of catalase. Analytical biochemistry. 1972;47:389-94. https://doi.org/10.1016/0003-2697(72)90132-7

[11] Packer L, Glazer. Method in enzymology. Vol 186 part B, Academic Press Inc New York. 1990:251.

[12] Beutler E, Duron O, Kelly BM. Improved method for the determination of blood glutathione. J Lab Clin Med. 1963;61:882-8.

[13] Bancroft JD, Gamble M. Theory and practice of histological techniques: Elsevier health sciences; 2008.

[14] Tamhane A, Dunlop D. Statistics and data analysis: from elementary to intermediate. 2000.

[15] Lillie R, Fulmer $\mathrm{H}$. Histol nthologic Technic and Practical Histoclzer7zistry. McGraw-Hill, New York; 1976.

[16] Pasqualotto EB, Agarwal A, Sharma RK, Izzo VM, Pinotti JA, Joshi NJ, et al. Effect of oxidative stress in follicular fluid on the outcome of assisted reproductive procedures. Fertility and sterility. 2004;81:973-6. https://doi.org/10.1016/j.fertnstert.2003.11.021

[17] Roshdy HM. Reproductive and Developmental Effects of Moxifloxacin on Female Mice and Embryos. The Egyptian Journal of Hospital Medicine. 2004;17:12-9. https://doi.org/10.21608/ejhm.2004.18153

[18] Korkmaz M, SARITAŞ ZK, BÜLBÜL A, Demirkan I. Effect of pre-emptive dexketoprofen trometamol on acute cortisol, inflammatory response and oxidative stress to hot-iron disbudding in calves. Kafkas Univ Vet Fak Derg. 2015;21:563-8.

[19] Meral Ö, Ercan N, Fidancı U. Lipid peroxidation level and antioxidant enzyme activities in septicemic calves. Ankara Üniversitesi Veteriner Fakültesi Dergisi. 2017;64:161-4. https://doi.org/10.1501/Vetfak_0000002793

[20] Pastore A, Federici G, Bertini E, Piemonte F. Analysis of glutathione: implication in redox and detoxification. Clinica chimica acta. 2003;333:19-39. https://doi.org/10.1016/S0009-8981(03)00200-6

[21] Kohanski MA, Dwyer DJ, Hayete B, Lawrence CA, Collins JJ. A common mechanism of cellular death induced by bactericidal antibiotics. Cell. 2007;130:797-810. https://doi.org/10.1016/j.cell.2007.06.049

[22] Halliwell. Free radicals and other reactive species in disease. 2015. https://doi.org/10.1002/9780470015902.a0002269.pub3

[23] Veerapandian S, Ghadevaru S, Jayaramachandran R. Veterinary pharmacovigilance evaluation on impact of enrofloxacin administration on antioxidant status in broiler chicken. International Journal of Current Microbiology and Applied Sciences. 2013;2:335-41.

[24] Kumbhar G, Khan A, Rampal S. Evaluation of gatifloxacin for its potential to induce antioxidant imbalance and retinopathy in rabbits. Human \& experimental toxicology. 2015;34:372-9. https://doi.org/10.1177/0960327114530743 
[25] Ore A, Olayinka ET. Influence of moxifloxacin on hepatic redox status and plasma biomarkers of hepatotoxicity and nephrotoxicity in rat. Biochemistry research international. 2015;2015. https://doi.org/10.1155/2015/192724

[26] Stancova V, Plhalova L, Blahova J, Zivna D, Bartoskova M, Siroka Z, et al. Effects of the pharmaceutical contaminants ibuprofen, diclofenac, and carbamazepine alone, and in combination, on oxidative stress parameters in early life stages of tench (Tinca tinca). Veterinární medicína. 2017;62:90-7. https://doi.org/10.17221/125/2016-VETMED

[27] Yakan S, Duzguner V, Aksoy O. Effects of Flunixin Meglumine on Oxidant and Antioxidant System after Disbudding with Caustic Paste in Calves. Acta Scientiae Veterinariae. 2018;46:9. https://doi.org/10.22456/1679-9216.88542

[28] Ellethy AT. Potential antitumor activity of nonsteroidal antiinflammatory drugs against Ehrlich ascites carcinoma in experimental animals. International Journal of Health Sciences. 2019;13:11.

[29] Channa M, Janjua M. Effects of ciprofloxacin on foetal hepatocytes. JOURNAL-PAKISTAN MEDICAL ASSOCIATION. 2003;53:448-50.

[30] Adikwu E, Brambaifa N. Ciprofloxacin cardiotoxicity and hepatotoxicity in humans and animals. 2012. https://doi.org/10.4236/pp.2012.32028

[31] Zimpfer A, Propst A, Mikuz G, Vogel W, Terracciano L, Stadlmann S. Ciprofloxacin-induced acute liver injury: case report and review of literature. Virchows Archiv. 2004;444:87-9. https://doi.org/10.1007/s00428-003-0917-9

[32] Ismail NH. Assessment of histopathological and histochemical changes in liver of pregnant female rats and their fetuses following Ciprofloxacin administration. J Egy Soc Toxcol. 2006;35:7-17.

[33] El Komy A., El-Meleh A., R. E, A. S. Effect of norfloxacin on fetal developments in pregnant female albino rats. World Journal of Pharmacy and Pharmaceutical Sciences. 2017;6:46-59.

[34] Choudhury D, Ahmed Z. Drug-associated renal dysfunction and injury. Nature clinical practice Nephrology. 2006;2:80-91. https://doi.org/10.1038/ncpneph0076

[35] Patterson GR, Capaldi D, Bank L. An early starter model for predicting delinquency. An earlier draft of this chapter was presented at the Earlscourt Conference on Childhood Aggression, Toronto, Canada, Jun 1988: Lawrence Erlbaum Associates, Inc; 1991.

[36] Al-faris OJ, Al-Shawi NN, Kako MD. Possible Cardiac Adverse Effects Induced by Therapeutic Doses of Ciprofloxacin in Juvenile Rats. Iraqi Journal of Pharmaceutical Sciences (P-ISSN: 1683-3597, E-ISSN: 2521 3512). 2012;21:94-7.

[37] Ramalakshmi S, Bastacky S, Johnson JP. Levofloxacin-induced granulomatous interstitial nephritis. American Journal of Kidney Diseases. 2003;41:e7. 1-e7. 5. https://doi.org/10.1053/ajkd.2003.50064

[38] Elkomy A, Aboubakr M, Medhat N. Some teratological effects of difloxacin in rats. Benha Veterinary Medical Journal. 2016;30:266-71. https://doi.org/10.21608/bvmj.2016.31373

[39] Wade LT, Kenna JG, Caldwell J. Immunochemical identification of mouse hepatic protein adducts derived from the nonsteroidal antiinflammatory drugs diclofenac, sulindac, and ibuprofen. Chemical research in toxicology. 1997;10:546-55. https://doi.org/10.1021/tx960153t

[40] Somchit N, Sanat F, Gan E, Shahrin I, Zuraini A. Liver injury induced by the non-steroidal anti-inflammatory drug mefenamic acid. Singapore medical journal. 2004;45:530.

[41] Black HE. Renal toxicity of non-steroidal anti-inflammatory drugs. Toxicologic pathology. 1986;14:83-90. https://doi.org/10.1177/019262338601400110

[42] Ebaid H, Dkhil MA, Danfour MA, Tohamy A, Gabry MS. Piroxicaminduced hepatic and renal histopathological changes in mice. Libyan Journal of Medicine. 2007;2:82-9. https://doi.org/10.3402/ljm.v2i2.4700 